\title{
НОВЫЕ ТЕНДЕНЦИИ РАЗВИТИЯ ГРАЖДАНСКО-ПРОЦЕССУАЛЬНОЙ СИСТЕМЫ КНР
}

\begin{abstract}
Аннотация. Гражданско-процессуальный кодекс Китая - один из основных актов государства, отражающий принцип стандартизации процесса гражданского судопроизводства. Действовавший Гражданско-прочессуальный кодекс КНР был разработан в 1991 г. В 2007 г. Правительство КНР внесло поправки, касающиеся надзора за гражданским судопроизводством и порядка исполнения принятых решений. Но вследствие быстрого экономического развития Китая количество новых типов гражданских дел непрерывно увеличивается, а существующая гражданско-прочессуальная система была не способна в полной мере удовлетворить требования правосудия. Новый Гражданско-процессуальный кодекс КНР вступил в законную силу в 2013 г.

В этом ГПК Китая закреплен принцип добросовестности, выступающий в качестве ориентира для судей и сторон по делу; созданы система судопроизводства общественных исков, система судопроизводства злонамеренных исков, система судопроизводства мелких исков, система помощи по защите прав и интересов третьей стороны и др.; усовершенствована система судопроизводства. Эти и другие вопросы нашли отражение в данной статье. Кроме этого, было прокомментировано новое содержание гарантии права сторон на подачу исков, основывающееся на новой процедуре принятия дела на рассмотрение, права ходатайствовать о пересмотре дела и системе предоставления доказательств.

Ключевые слова: КНР, гражданский, иск, основной принцип, злонамеренный иск, мелкий иск, право подачи иска, пересмотр дела, доказательство, новые тенденции.

DOI: 10.7256/1729-5920.2014.1.10460
\end{abstract}

$\Gamma$ ражданско-процессуальный кодекс - это основные правила судебных разбирательств в народном суде во время гражданского судопроизводства между гражданами, юридическими лицами и организациями. ГПК Китая имеет огромное значение для разрешения гражданско-правовых споров и сохранения стабильности общества.

Вследствие быстрого экономического развития Китая количество новых типов гражданских дел непрерывно увеличивается, но существующая гражданско-процессуальная система уже не способна в полной мере удовлетворить требования правосудия. Гражданско-процессуальный кодекс КНР был при- нят в 1991 г., в 2007 г. в него были внесены поправки. 31 августа 2012 г., стремясь разрешить конфрликты и споры, обеспечить справедливость и более удобную процессуальную систему, Правительство КНР снова внесло изменения в Кодекс. 1 января 2013 г. вступил в законную силу новый Гражданско-процессуальный кодекс КНР.

Гражданско-процессуальный кодекс 2013 г. одновременно учитывает такие ценности судопроизводства, как справедливость и эффективность. Коренной переработке подверглись более 100 статей, при этом большое внимание было уделено законодательному отражению принципа добросовестности; соз-

(C) Ха Шуцзюй

* Доктор юридических наук, профессор Хэйлунцзянского университета

[hashuju@163.com]

150080, КНР, провинция Хэйлунцзян, г. Харбин, район Нань Ган, ул. Сюе Фу, д. 74.

Статья подготовлена в рамках исследовательского проекта Китайско-российского центра инновационного взаимодействия и гуманитарного сотрудничества в 2012 г. на тему "Исследование гражданского права и торгового права на фоне китайско-русского стратегического взаимодействия» (№ 2012ZD006) 
даны несколько важных систем судебных процессов (судопроизводство по общественным искам и судопроизводство по мелким искам); закреплено право третьей стороны отзывать иск; система гарантии актов; появились система судебного утверждения, реализация системы обеспечительных интересов и другие системы судопроизводства. Существенные изменения внесены в принципы гражданского судопроизводства, систему принятия исков к рассмотрению, систему юрисдикции, систему посредничества при урегулировании споров, систему доказательств; были предусмотрены: упрощенный порядок, особый порядок, порядок надзора за судебными решениями, исполнительный порядок и порядок рассмотрения дела, связанного с иностранными элементами.

\section{Принцип добросовестности}

Недостаток доверия стал одной из серьезных проблем в современном Китае. Для того чтобы восстановить доверие к судопроизводству, принцип добросовестности в судопроизводстве КНР был выделен в ГПК в качестве основного ${ }^{1}$. Он выполняет двойную роль: с одной стороны, предоставляет судье свободу действий, а с другой стороны - ограничивает его полномочия. Кроме этого, принцип добросовестности уменьшает судебные издержки. Во время судопроизводства этот принцип распространяется на лиц, участвующих в деле. И лица, участвующие в деле, и суд должны соблюдать принцип добросовестности, в противном случае на них возлагаются соответствующие правовые последствия.

Являясь правилом вынесения решения в гражданском процессе, принцип добросовестности в предоставлении судье свободы действий и ограничении его полномочий проявляется в двух аспектах: первый - рассмотрение доказательств и вынесение решения; второй - распределение бремени доказывания. Проблема системы доказательства является очень сложной, положения Кодекса не могут учитывать всевозможную практику. При рассмотрении доказательств и вынесении решения судья должен быть объективным, поэтому он обязан придерживаться общих норм доказательственного права. Факты и доказательства, независимо от того, какой

В ст. 13 ГПК Китая говорится: «Гражданско-процессуальный кодекс должен обеспечивать принцип добросовестности». стороной они были предоставлены, должны быть объектом рассмотрения. Судья должен гарантировать беспристрастность, он не может быть субъективным, не должен иметь личных симпатий или антипатий, обязан исключить любые факторы и помехи, которые могли бы помешать рассмотрению судебного дела. Если суд во время рассмотрения и вынесения решения не придерживается принципа добросовестности, то стороны могут подать апелляционную жалобу.

При распределении бремени доказывания принцип добросовестности также может играть важную роль. Когда подлинность фрактов по делу неизвестна, судье все равно приходится вынести решение. В этой ситуации он должен определить, на какую сторону ляжет бремя доказывания подлинности фактов. Гражданско-процессуальный кодекс определил: «Каждая сторона должна доказывать те обстоятельства, на которые ссылается». Это является основным принципом ответственности. В ст. 7 Некоторых положений Верховного народного суда КНР, касающихся доказательств в гражданском процессе сказано: в законе нет конкретных положений, поэтому когда нет возможности определить, на ком лежит бремя доказывания, суд, на основании принципов справедливости и добросовестности, вправе сопоставить правоспособность сторон предоставлять доказательства и определить, на кого ляжет бремя доказывания. Тем самым судья подтверждает важную роль принципа добросовестности при распределении бремени доказывания. Являясь нормой поведения, принцип добросовестности также может и ограничивать свободу действий судьи. Данный принцип также требует от судьи, который осуществляет свои полномочия, обеспечить справедливость и добросовестность и действовать из добрых побуждений.

Суд является одним из государственных органов, поэтому в случае, если его решения не будут соответствовать принципу добросовестности, судебная власть потеряет авторитет, и граждане будут испытывать недоверие к закону. Более того, могут появиться сомнения в отношении всей государственной системы, что может пошатнуть основу государства и будет препятствовать развитию правовых институтов. Для сторон в судебном деле принцип добросовестности является нормой поведения. Этот принцип требует от них исполнения реального долга, исключение действий, наносящих вред при предоставлении доказательств, запрещение злоупотребления юридическими процедурами (затягивание дела). 
Принцип добросовестности может стать руководством для судей и сторон по делу; более того, этот принцип отвечает тенденциям развития социальной целостности и единства общественных интересов. Он может наилучшим образом урегулировать баланс между сторонами судебного процесса и общественными интересами.

\section{Новые системы в Гражданско- процессуальном кодексе и совершенствование существующих систем}

Система судопроизводства общественных исков. В течение долгих лет в Китае отсутствовала нормативная правовая база, регулирующая сфреру окружающей среды. Из-за частых случаев ее загрязнения был нанесен огромный ущерб общественным интересам, но, к сожалению, мало кто предъявляет иски по этому поводу. В Китае Закон «Об охране окружающей среды» предусматривает: все организации и граждане имеют обязательства по защите окружающей среды; загрязнение и нанесение вреда окружающей среде гражданами и организациями преследуется по закону, вплоть до возбуждения дела. Но «изобличение и предъявление иска» имеют разную природу с «правом подачи иска», прописанным в Кодексе. Гражданско-процессуальный кодекс требует, чтобы истец имел непосредственную связь с общественными интересами, фигурирующими в деле и являющимися для него материальными интересами, тогда как судопроизводство по общественным экологическим искам защищает больше общественные экологические интересы, и истец лично не имеет непосредственной связи с делом. В действительности такая затруднительная обстановка китайского законодательства совсем не влияет на поиск судебной практики для системы судопроизводства по указанным искам.

Приведем пример дела по общественному экологическому иску. 13 ноября 2005 г. на одном из заводов нефтехимической компании г. Цзилинь произошел взрыв. Он вызвал серьезное загрязнение воды реки Сунгари, пострадали жизни миллионов людей, проживающих вдоль реки. 7 декабря 2005 г. председатель Всекитайского профессионального комитета по контролю окружающей среды и ресурсов Ван Цзин и другие лица, «представляя интересы реки Сунгари», начали судебное разбирательство, которое в судебной сфере считалось примером судопроизводства по общественному экологическому иску. Будучи профеессиональными юристами, Ван Цзинь и другие члены хорошо понимали, что если строго придерживаться положения о «непосредственной связи с материальными интересами», указанными в Гражданско-процессуальном кодексе, то суд не сможет принять это дело на рассмотрение. Таким образом, они вовлекли в дело осетровых рыб, остров Тайяндао и другие природные объекты в качестве «истцов», создали своего рода новую систему «непосредственных материальных интересов». После всесторонней и тщательной подготовки судебных документов они подали в суд исковое заявление. Несмотря на то, что суд вынес решение не принимать дело на рассмотрение по причине несоответствия предмета иска, главное значение этого дела в том, что в КНР произошли сдвиги в судопроизводстве по общественным экологическим искам.

По причине актуальности и важности защиты общественных интересов, а также основываясь на судебной практике, появилась необходимость внести изменения в Кодекс. В ГПК применительно к системе судопроизводства по общественным искам введены соответствующие положения: «В отношение действий, связанных с загрязнением окружающей среды, покушением на законные права и интересы многочисленных потребителей и других действий, наносящих вред общественным интересам, установленные законом учреждения и соответствующие организации могут подавать иск в народный суд» (ст. 55).

Множество ученых и экспертов считают, что становление подобной системы «распахнет двери» для судопроизводства по делам об общественных интересах КНР. Однако в новом ГПК нет четких положений, касающихся субъекта судопроизводства по общественным искам. Невозможно определить предмет иска, поэтому судопроизводство по таким делам может остаться только на бумаге. Что касается предмета возбуждения иска об общественных интересах, то нужно дождаться дальнейшего уточнения положений, которые должны быть сделаны во время разработки соответствующих законов. Кроме этого, требуется создать судебную практику по таким делам.

Почему же нынешние изменения, внесенные в Гражданско-процессуальный кодекс, не затронули проблему определения предмета иска об общественных интересах? Нужно сказать, что с этим ничего не поделаешь, так как между пониманием вопроса с точки зрения науки и с точки зрения практики существует 
большая разница. Научное сообщество считает, что прокуратура обладает компетенцией по возбуждению дела об общественных интересах, однако практики с этим не согласны. Последние полагают, что уполномоченные органы прокуратуры, возбуждая такие дела, могут ослабить другие надзорные функции прокуратуры. В связи с этим в Гражданско-процессуальном кодексе нет четких положений о том, может ли прокуратура возбуждать дела об общественных интересах.

Новый закон также не наделяет частное лицо полномочиями подавать иски, касающиеся общественных интересов. По этому поводу есть два соображения: отдельный гражданин может злоупотреблять полномочиями для защиты общественных интересов, тем самым это может привести к массовым подачам подобных исков. Если гражданину в действительности причинен вред по причине загрязнения окружающей среды или по другим причинам, то он становится лицом, имеющим непосредственные материальные интересы, и может подавать иск в суд. Данным иском может быть достигнута и цель защиты общественных интересов ${ }^{2}$.

Совершенствование системы прокурорского надзора за гражданскими делами. В докладах на XV-XVII съездах ВСНП Коммунистической партии КНР были озвучены планы в отношении реформы судебной системы Китая. В докладе на XV съезде партии была сорормулирована цель реформы - улучшение состояния судебной системы Китая, следовало «гарантировать право судебных органов на законном основании, независимо и беспристрастно осуществлять юрисдикцию и право прокурорского надзора».

В декабре 2004 г. ЦК КПК постановил, что реформа должна решить такие задачи, как «четкое определение пределов правового надзора народной прокуратуры за гражданскими и административными делами, а также совершенствование соответствующего порядка». Было принято решение начать всестороннее реформирование механизма судебной системы. В 2007 г. Постоянный комитет ВСНП внес поправки в Гражданскопроцессуальный кодекс КНР, направленные в основном на совершенствование системы пересмотра гражданских дел и исполнительной системы, повышение способности оказания помощи для подачи встречной апелляции

Тан Вэйцзянь. Общественные иски смогут контролировать загрязнение окружающей среды // Вечерняя газета «ПРАВО». 2013. 20 янв. в отношении прав сторон. На XVII съезде партии был подготовлен новый план реформы судебной системы, требовалось «улучшить распределение служебных полномочий системы правосудия, стандартизировать акты судебной власти, а также создать беспристрастную, высокоэффрективную и авторитетную социалистическую судебную систему» .

В декабре 2008 г. Центральное радио транслировало «Замечания ЦК КПК по некоторым вопросам углубления реформы судебной системы и рабочего механизма». Были выдвинуты более 60 разнообразных задач по реформированию, было повторно сказано о «совершенствовании механизма определения пределов правового надзора прокуратуры за гражданскими и административными делами, а также совершенствовании соответствующего порядка».

Гражданско-процессуальный кодекс 2013 г. как раз был разработан на основе такого политического курса. Новый кодекс был создан на основе Конституции Китайской Народной Республики, согласно которой прокуратура является «государственным органом судебного надзора».

Прокурорский надзор за гражданскими делами, являясь одной из систем, используемой для надзора за служебными полномочиями, может иметь достаточную жизненную силу только в связке с обоснованными законными требованиями сторон. Новый Гражданскопроцессуальный кодекс расширил пределы надзора прокуратуры за гражданским судопроизводством. Прежняя фрормулировка «Народная прокуратура имеет право надзора за решениями по гражданским делам» изменена на новую - «Народная прокуратура имеет право надзора за гражданскими исками». Таким образом, исполнительные действия в гражданском судопроизводстве также попали под правовой надзор.

По ГПК народная прокуратура в отношении вынесенных и уже вступивших в законную силу решений народных судов всех уровней, обнаружив новые доказательства, достаточные для отмены первоначального решения, обнаружив ошибки или мировые соглашения, наносящие вред национальным или общественным интересам, должна сделать процессуальный отвод. Местные народные прокуратуры любой инстанции не могут напрямую обратиться в народный суд той же инстанции с апелляцией. Органы прокуратуры одной инстанции могут обратиться в народный суд той же инстанции с предложением осуществления прокурорского надзора, также у них есть воз- 
можность ходатайствовать в народную прокуратуру вышестоящей инстанции о подаче апелляции в народный суд той же инстанции.

В отношении противозаконных действий судьи во время других судебных процессов, не попавших под надзор, народные прокуратуры всех инстанций имеют право войти с предложением об осуществлении прокурорского надзора в народный суд той же инстанции (ст. 208 ГПК КНР).

Предложение об осуществлении прокурорского надзора стало новым положением Гражданско-процессуального кодекса 2013 г. Органы прокуратуры могут выступать с инициативой осуществления «права выступать с предложением об осуществлении прокурорского надзора». Кроме этого, стороны также имеют право выдвинуть предложение об осуществлении прокурорского надзора или могут подать апелляцию в народную прокуратуру, если: 1) народный суд отклонил их прошение о пересмотре дела или просрочил вынесение решения о пересмотре дела; 2) стороны считают, что во время пересмотра дела или во время вынесения решения были допущены явные ошибки (ст. 219 ГПК КНР).

Предложение об осуществлении прокурорского надзора - это новый вид контроля; он означает, что народная прокуратура может осуществлять надзор за всеми судебными процессами в народных судах. Если прокуратура посчитает, что во время судебного процесса имели место противозаконные действия, то она может выступить с предложением к этому суду о прокурорском надзоре и может потребовать исправления допущенных ошибок или же потребовать от суда придерживаться законных действий во время судопроизводства.

С 1991 по 2013 гг. система надзора за гражданским судопроизводством, осуществляемым органами прокуратуры, Гражданскопроцессуальным кодексом была всесторонне усовершенствована и укреплена: 1) с точки зрения принципа надзора: формулировка положения «надзор за решениями по гражданским делам» сменилась на «надзор гражданских исков»; 2) с точки зрения способа надзора: единственно возможный способ, такой как подача апелляции, дополнил метод прокурорского надзора; 3) с точки зрения источника дела: раньше органы прокуратуры обнаруживали ошибки в уже вступивших в силу решениях по гражданским делам, а сейчас стороны могут законно ходатайствовать в прокуратуру о подаче апелляции; 4) с точки зрения объекта апелляции: раньше подавать апелляцию мож- но было только в отношении судебного решения, вступившего в силу, а сейчас апелляцию можно подавать и на мировое соглашение.

Все эти изменения предвещают то, что органы прокуратуры превращаются из ограниченного в настоящее время инструмента по надзору за гражданскими делами в достаточно зрелую судебную систему.

Система судопроизводства по злонамеренным искам и система оказания помощи для защиты прав третьей стороны, которой был нанесен ущерб. Что такое судопроизводство по злонамеренным искам? К примеру: истец в ходе бракоразводного процесса при разделе имущества хочет получить большую долю, он заключает злонамеренное соглашение со своими друзьями, которые подают иск «о взыскании задолженности» в размере 300. 000 тыс. юаней. Затем они добиваются решения суда по этому делу о совместной ответственности должников. Таким образом, оба супруга обязуются оплатить до этого отсутствующий долг, поэтому один из супругов получает меньшую часть имущества, а другой после развода и разделения имущества остается в прибыли.

В последние годы обстановка в Китае со злонамеренными исками принимает все больший оборот. Злонамеренные иски представляют собой законный гражданский процесс по получению неправомерной выгоды. Такие злонамеренные иски растрачивают ресурсы судебной системы, а также подрывают ее авторитет. Прописав в законе положения о злонамеренных исках, а также положения о злонамеренных соглашениях, можно снизить их количество путем назначения уголовного наказания или увеличения ответственности за такие действия.

Гражданско-процессуальный кодекс постановил: «иски, таящие в себе злонамеренные соглашения между сторонами, участвующими в деле, попытки ущемления законных прав и интересов других лиц путем подачи иска, мирового соглашения или любыми другими способами должны быть отклонены народными судами. Кроме этого, лица, подающие такие иски, должны быть наказаны штрафом или арестом в зависимости от тяжести иска. Лица, в действиях которых был усмотрен состав преступления, подлежат уголовной ответственности». «Лицо, являющееся должником по решению суда, заключившее злонамеренное соглашение с другими лицами и уклоняющееся от исполнения долга, установленного правовыми документами путем подачи иска, арбитража, мирового соглаше- 
ния или любыми другими способами, должно быть наказано народными судами штрафом или арестом в зависимости от тяжести иска. Лица, в действиях которых был усмотрен состав преступления, подлежат уголовной ответственности» (ст. 112 и 113 ГПК КНР).

До Гражданско-процессуального кодекса 2013 г. основным методом оказания помощи для защиты третьей стороны, которой был причинен ущерб по причине подачи фриктивных исков, был пересмотр дела и вынесение нового решения. Но проблема в том, что условия прошения о пересмотре дела были очень жесткими, а начало такого процесса было затруднительным. Все это создавало помехи для оказания помощи по защите прав третьей стороны.

В 2012 г. ряд специалистов и экспертов выступили с предложениями относительно злонамеренных исков, согласно которым следовало применять штрафные санкции, арест или привлечение к уголовной ответственности на основании закона в качестве меры пресечения за подачу вредоносных гражданских исков. Кроме этого, также необходимо было предусмотреть в Гражданско-процессуальном кодексе метод оказания помощи третьей стороне, которой нанесен ущерб ее законным правам и интересам. «Если сравнивать с пересмотром дела, то с точки зрения процесса для третьей стороны стало более удобно подавать иск об отмене решения, а это, в свою очередь, благоприятно сказывается на формировании законного метода третьей стороны защищать свои законные права и интересы»³.

Судопроизводство по мелким искам по схеме «решение первой инстанции - окончательное решение». Конфрликты по мелким делам, как правило, не очень острые, фракты по ним ясны, а правоотношения просты. Если процесс разрешения спора чрезмерно сложный, а сам спор трудноразрешим, то все это может оказать влияние на стабильность общества. Для того чтобы своевременно разрешать споры и повысить эффективность судопроизводства, Гражданско-процессуальный кодекс постановил, что во время рассмотрения простых гражданских дел народные суды первой инстанции, а также трибуналы должны осуществлять рассмотрение дел по схеме «решение первой инстанции - окончательное решение», в случае если сумма предмета до-

Сюн Юэминь. КНР намеривается внести поправки в Кодекс для снижения количества злонамеренных исков // Сайт ВСНП http://www.npc.gov.cn/huiyi/ cwh/1128/2012-08/28/content_1734472.htm. говора составляет менее $30 \%$ от прошлогодней среднегодовой заработной платы занятого населения в любой провинции, автономном районе или городе центрального подчинения (ст. 162 ГПК КНР).

Создание системы судопроизводства по мелким искам является преимуществом и новшеством судебной системы. Она была создана для разрешения всевозможных мелких конфликтов, связанных с защитой прав потребителей, простой фрормой кредитования населения, фринансовыми кредитами на небольшие суммы, спорами по ДТП, а также с нанесением небольшого ущерба имуществу и другими мелкими делами.

Но наряду с этим мы не можем обойти вопрос, связанный с тем, как обеспечить сохранение права сторон на апелляцию ввиду упрощения процесса. Схема «решение первой инстанции - окончательное решение» предусматривает пересмотр дела, и с точки зрения процесса предоставляет хорошую помощь для защиты прав и интересов сторон, а также гарантирует право сторон на обжалование вынесенного решения (подача апелляции) и право на пересмотр дела.

Система судопроизводства по мелким искам имеет огромное значение для повышения эфффективности судебного разбирательства, снижения судебных издержек с обеих стороны и рационального использования судебных ресурсов.

\section{Право сторон на подачу (возбуждение) иска}

Право на возбуждение иска является правом судебной защиты сторон. Гражданско-процессуальный кодекс, как уже говорилось, предусматривает новые системы судопроизводства. Кроме того, содержит улучшенные, основанные на прежних, системы, например гарантии права сторон на возбуждение иска, реформированные нормы доказательственного права, стандартизированные процедуры принятия исков к рассмотрению. В Кодекс добавлены положения о судебном утверждении мировых соглашений и т.д.

Стандартизация процесса принятия иска судом к рассмотрению и укрепление гарантий сторон на право подачи апелляции и право пересмотра дела. Гарантия права сторон на подачу апелляции является ведущей идеей изменений Гражданско-процессуального кодекса. Новый Гражданско-процессуальный кодекс стандартизировал процесс 
принятия исков к рассмотрению народными судами и обязал суд выносить постановление с четкими и убедительными аргументами в случае отказа от принятия дела; тем самым Кодекс гарантировал право сторон на подачу апелляции. Если истец недоволен отказом от принятия дела, он может обратиться в вышестоящую инстанцию (ст. 123 ГПК КНР); таким образом, опять же гарантируется право сторон на подачу апелляции.

Гражданско-процессуальный кодекс 1991 г. предусматривал, что стороны имеют право выбирать между народным судом первой инстанции и народным судом следующей инстанции для подачи ходатайства о пересмотре дела. После изменений Гражданско-процессуального кодекса в 2007 г. было закреплено: если граждане сочтут, что в решении, вступившем в законную силу, имеются недочеты или ошибки, то они могут обратиться только в народный суд следующей инстанции с вопросом о пересмотре дела. В то время считалось, что народный суд следующей инстанции должен исправлять соответствующие ошибки. По этой причине огромное количество пересматриваемых дел оказали огромное давление на народные суды вышестоящей инстанции и Верховный народный суд. Вследствие этого в Гражданско-процессуальном кодексе 2013 г. был использован компромиссный прием было предусмотрено: если граждане сочтут, что в решении, вступившем в законную силу, имеются недочеты или ошибки, они могут обратиться в народный суд следующей инстанции с вопросом о пересмотре дела. По искам, в которых фригурирует большое количество лиц с одной стороны или по искам, в которых представители обеих сторон являются гражданами, можно ходатайствовать о пересмотре дела в народный суд первой инстанции (ст. 199 ГПК КНР).

Стандартизация процедуры получения доказательств судьей, выбор наиболее справедливого, разумного и многостороннего метода решения вопроса, связанного с опозданием представления доказательств. В простонародье говорят: «Если уж затеял судебное дело, так представь доказательства, а доказательства, представленные простым народом, определяют выигрыш в судебном деле».

Для предотвращения таких явлений судебной практики, когда после представления сторонами доказательств суду эти доказательства теряются, в новом Кодексе предусмотрено, что народный суд после получения доказательств от сторон обязан выдать им квитанцию, заверенную подписью и печатью канцелярии, в которой будет четко написано наименование доказательства, количество страниц, количество экземпляров, отмечено, оригинал это или копия доказательства, а также время получения (ст. 66 ГПК КНР). Такое положение связывает судью обязательством и предотвращает порчу доказательств по причине беспечности или корыстных побуждений судьи, в противном случае это может иметь для сторон неблагоприятные последствия. Смысл этого правила заключается в том, чтобы и суд и стороны были уверены в материалах доказательства, а в ходе будущего судебного разбирательства представленные доказательства не оспаривались.

Судебное дело имеет ограничение по времени, срок представления доказательств является справедливым для обеих сторон. В 2001 г. Верховный народный суд издал постановление «Некоторые положения относительно доказательств по гражданским делам». Данное постановление в первую очередь предусматривало четкое определение сроков представления доказательств, но в судебной практике такое положение не всегда соблюдалось. В этот раз было добавлено следующее требование: стороны должны своевременно представлять доказательства своей точки зрения по делу. В отношении стороны, опоздавшей с представлением доказательств, народный суд должен обязать объяснить причину задержки. В отношении лиц, отказавшихся объяснять причину, или лиц, у которых не было причин на задержку представления доказательств, народный суд может отказать в принятии доказательств или он может принять данное доказательство, сделав выговор или применив штрафные санкции (ст. 65 ГПК КНР).

Гражданско-процессуальный кодекс содержит определенный набор правовых последствий нарушения сроков представления доказательств, а не только единственный способ - отказ от принятия доказательств. Таким образом, сохраняется принцип ограничения сроков представления доказательств, а также обеспечивается возможность включить в судебный процесс важные доказательства, тем самым гарантировав справедливость. Отказ от принятия доказательств является самой строгой мерой в отношении просрочки их представления; такое положение дел в судебной практике может максимально смягчить коллизию процессуальной и реальной справедливости, а это, в свою очередь, является огромным преимуществом. 
Другие правила защиты права сторон на подачу апелляции. Прозрачность и открытость судебной системы является символом современного правосудия. Новый Гражданско-процессуальный кодекс усовершенствовал систему открытости информации относительно судебных решений, что, в свою очередь, играет огромную роль в повышении качества судопроизводства. Граждане могут просматривать вступившие в силу судебные решения и указания (кроме решений, содержащих государственную или коммерческую тайну либо касающихся неприкосновенности личной жизни). Вместе с тем новый Кодекс более четко определил, что в судебных решениях и указаниях должны быть точно прописаны последствия таких решений или постановлений, а также причина их принятия (ст. 152 и 156 ГПК КНР). В реальности, указание причины судебного решения необходимо для повышения чувства ответственности судей, стандартов при разработке судебного решения, исчерпывающего его обоснования, общего качества работы и содействия открытости.

Для того чтобы установить факты, четко разграничить правду и ложь, защитить права и законные интересы сторон, основываясь на судебной практике и всесторонних предложениях, новый Кодекс наделил стороны правом начала процесса экспертизы. Когда стороны имеют возражения в отношении экспертизы или народный суд считает необходимым выступление эксперта в суде, эксперт обязан явиться в суд в качестве свидетеля. Согласно извещению Народного суда, если эксперт отказывается выступать в суде в качестве свидетеля, то заключение экспертизы не будет считаться основанием для установления фрактов (ст. 152 и ст. 156 ГПК КНР).
Исполнение решений - наболевший вопрос, долгое время мучающий суды. После победы в суде, если попался, например, недобросовестный заемщик, его нельзя обязать исполнить решения. Такая ситуация является мучительной для сторон, и суды ничего не могут с этим сделать. Для дальнейшего разрешения проблемы новый Кодекс усилил исполнительные действия, увеличил наказание недобросовестных заемщиков и предусмотрел возможность немедленного исполнения решения суда. Кроме этого, Кодекс повысил сумму штрафра за отказ от исполнения вступивших в силу судебных решений или постановлений. Для частного лица сумма штрафа повысилась с 10000 юаней до 100000 юаней; для организации верхний предел штрафа повысился с 300000 юаней до 1000000 юаней (ст. 115 и ст. 240 ГПК КНР).

Кроме того, Гражданско-процессуальный кодекс ограничил передачу юрисдикции нижестоящей инстанции, определил метод электронной передачи информации, добавил систему гарантии действий и серию других систем, способствующих осуществлению права сторон на подачу апелляции.

Положения Гражданско-процессуального кодекса КНР 2013 г. больше соответствуют концепциям справедливости и эффрективности, но каковы же социальные последствия и его роль в этом? Для ответа на поставленный вопрос мы должны дождаться результатов анализа судебной практики. Для повышения общественного доверия к системе правосудия не только необходимо иметь здоровую правовую систему, но и придерживаться правовых норм, опираясь на полномочия и права органов юстиции и правоохранительных органов.

\section{Библиография}

1. Сюн Юэминь. КНР намеревается внести поправки в Кодекс для снижения количества злонамеренных исков // Сайт ВСНП http://www.npc.gov.cn/huiyi/cwh/1128/2012-08/28/ content_1734472.htm.

2. Тан Вэйцзянь. Общественные иски смогут контролировать загрязнение окружающей среды // Вечерняя газета «ПРАВО». 2013. 20 янв.

\section{References}

1. Syun Yuemin'. KNR namerevaetsya vnesti popravki v Kodeks dlya snizheniya kolichestva zlonamerennykh iskov // Sait VSNP http://www.npc.gov.cn/huiyi/cwh/1128/2012-08/28/ content_1734472.htm.

2. Tan Veitszyan'. Obshchestvennye iski smogut kontrolirovat' zagryaznenie okruzhayushchei sredy // Vechernyaya gazeta «PRAVO». 2013. 20 yanv. 